\title{
Automatic Irrigation System Using IOT
}

\author{
Sharada kulkarni and Rekha Mulagund
}

\begin{abstract}
The Internet of Things (IoT) is a system of interrelated computing devices, mechanical and digital machines, objects, animals or people that are provided with unique identifiers and the ability to transfer data over a network without requiring human-to-human or human-tocomputer interaction. Agriculture plays the important role in INDIAN economy. The most important thing which is needed for the irrigation is water. This proposal discussed about how the water can be efficiently used for agriculture. According to this proposal Real Time Clock(RTC) is used to control the motor in the real time. First the ON time and OFF time of the motor is send from the android application via GPRS modem. Once the ON and OFF timings are reached the controller, the motor continuously starts and stops in that particular time interval in the by using RTC. Temperature and moisture values of the irrigation area are continuously monitored and the values are send to the android application via GPRS modem. If the temperature and moisture values are beyond the certain limit an alert notification will be send to the farmer. If the farmer wish to control the motor remotely it is possible by pressing the $O N$ and OFF button given in the android application.
\end{abstract}

Keywords--- IOT, RTC, GPRS Modem, Android Application.

\section{INTRODUCTION}

A griculture plays a vital role in India's economy.

Over 58 per cent of the rural households depend on agriculture as their principal means of livelihood. Agriculture, along with fisheries and forestry, is one of the largest contributors to the Gross Domestic Product (GDP).The Internet of Things (IoT) is transforming the agriculture industry and enabling farmers to contend with the enormous challenges they face. The industry must overcome increasing water shortages, limited availability of lands, difficult to manage costs, while meeting the increasing consumption needs of a global population that is expected to grow by $70 \%$ by 2050 .New innovative IoT applications are addressing these Issues and increasing the quality, quantity, sustainability and cost effectiveness of agricultural production. The automated irrigation system was mainly developed to optimize the water usage for Agricultural lands. Previous technologies are developed by using distributed wireless sensor networks. Temperature and moisture sensors are fixed under the root zone of the plants to find the humidity present in the corps. Temperature and moisture data are transmitted to the web

Sharada kulkarni, Student, Dept of CSE, SKSVMACET LaxmeshwarIndia.E-mail:sharadakulkarni69@gmail.com

Rekha Mulagund, Student, Dept of CSE, SKSVMACET LaxmeshwarIndia.E-mail: rekhalm123@gmail.com

DOI:10.9756/BIJSESC.8247 page by using the GPRS technology we can access and view the data's and also an alert SMS will be send to the particular mobile when these data's are exceeded to the threshold values.[1] Currently, distributed wireless sensor network plays significant responsibility in civilizing agricultural production and mitigating the agony of farmers. The rain water sensor and $\mathrm{pH}$ sensor is used to calculate the climatic conditions in rainy season. PIC microcontroller is used to gather the sensor's data [2]. In this system ZIGBEE module is used to transmit and receive the data wirelessly. Photovoltaic cells are used to power up the system. Currently, some of the irrigation systems are operated manually, some are operated automatically. The current systems are mostly depends on Computer based, Low and high tech principles, Real time based etc. This system is not cost effective. The climatic conditions around the agriculture lands cannot be measured properly by the existing techniques. It cannot maintain the real time intervals and the self help compatibility is very low with big scale systems which are complex.

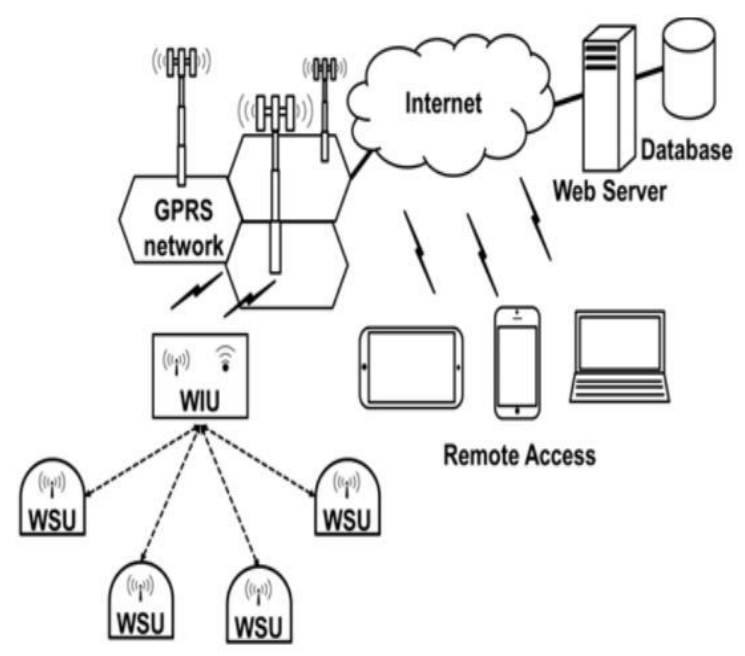

Figure 1: Irrigation System

\section{RELATED WORK}

Several studies have suggested so many approaches that increase the efficiency of the automated irrigation system using wireless sensor networks to reduce the power consumption by using low voltage sensors. Automatic irrigation system using wireless sensor networks and GPRS, in this method PIC16F877A microcontroller unit has been used to control the entire system. The operating voltage of the PIC is quiet high compared to other microcontrollers [1]. Here ZIGBEE module is used to transmit the sensor's information while the range of the ZIGBEE module is very low compared to other devices. Water-Saving Irrigation System Based on Automatic Control by Using GSM Technology, In this proposed work an embedded system for automatic control of 
irrigation. This project has wireless sensor network for realtime sensing and control of an irrigation system [3]. This system provides uniform and required level of water for the agricultural farm and it avoids water wastage. These papers have real time sensing and control of an irrigation system. When the condition of water in the agricultural farm is abnormal then the system automatically switches ON the motor. When the water level reaches normal level the motor automatically switch OFF. In this project they are interfacing microcontroller through temperature sensor, humidity sensor and also interfacing to GSM through MAX 232. Arduino Based Automatic Plant Watering System, This project uses Arduino board, which consists of ATmega328 Microcontroller.

It is programmed in such a way that it will sense the moisture level of the plants and supply the water if required. This type of system is often used for general plant care, as part of caring for small and large gardens. Normally, the plants need to be watered twice daily morning and evening. So, the microcontroller has to be coded to water the plants in the greenhouse about two times per day. For most people it becomes challenging to keep them healthy and alive. To accommodate this challenge they have developed a prototype, which makes a plant more self-sufficient, watering itself from a large water tank. The pro-To type reports status of its current conditions and also reminds the user to refill the water tank. Project deals about automatic irrigation system using internet of things (IOT) uses arduino as a controller to control the entire system. Main advantage of this system is using a real time clock (RTC). which irrigates the plants continuously. Instead of using ZIGBEE here GPRS is used to control the system from anywhere by using android application.

\section{AUTOMATIC IRRIGATION SYSTEM}

This method consists of two modes. Manual mode and automatic mode. In manual mode motor ON time and OFF time are send to the microcontroller unit from the android application via GPRS modem through the assigned IP address. In automatic mode which is used to control switching $\mathrm{ON}$ and OFF of the motor. The temperature and moisture sensor values are continuously monitored and readings are send to the android application. If the temperature and moisture values are beyond the threshold values an alert SMS will be send to the farmer. If the farmer wishes to switch ON the motor then it is done by opening android application in automatic mode and control the motor. The sensor information is transmitted to assigned IP address. In android application an web UI is created based on the assigned IP address. The android UI which allows the farmers to control the entire system.

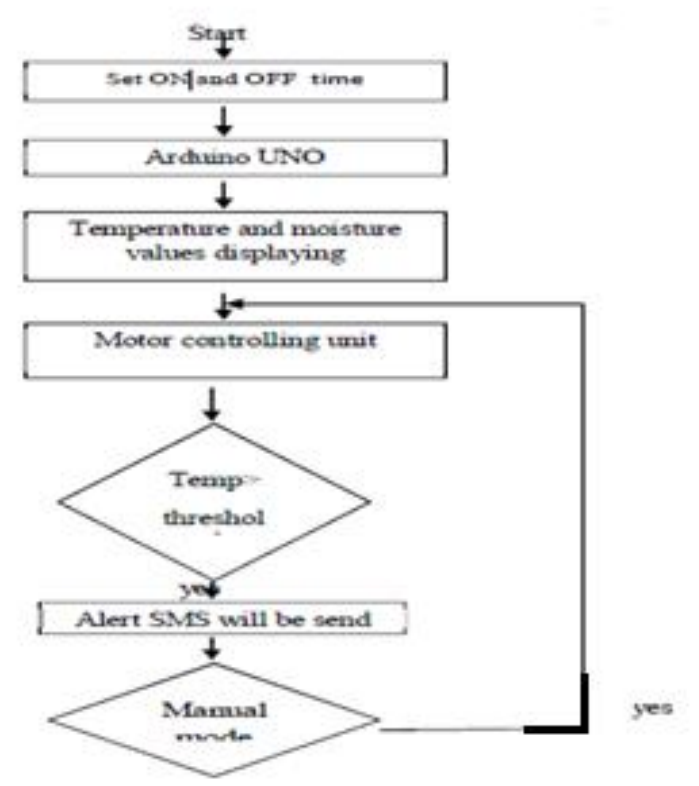

Figure 2: Flowchart

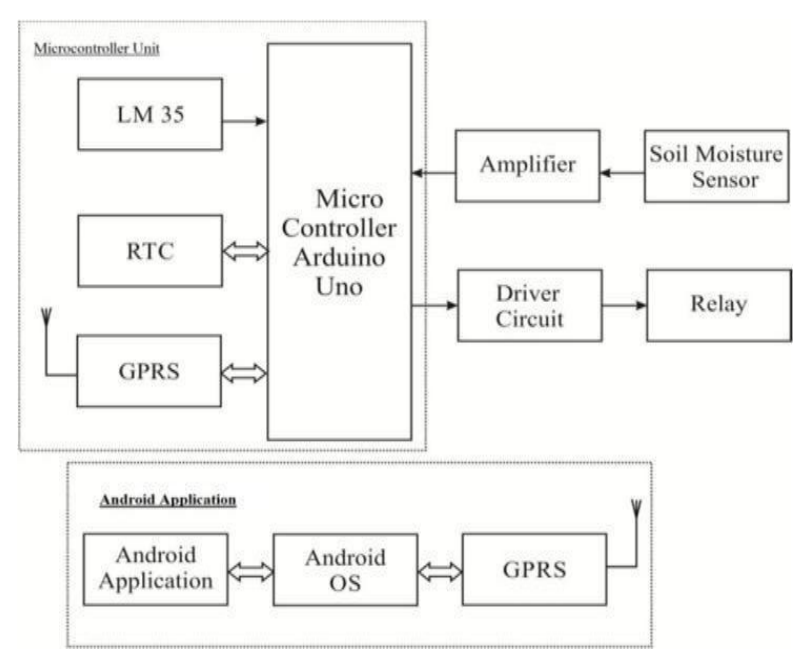

Figure 3: Block Diagram

The Arduino Uno is a microcontroller board based on the ATmega328. It accepts 14 digits Input/output pins (of which 6 can be used as PWM outputs), 6 analog inputs, a $16 \mathrm{MHz}$ crystal oscillator, a USB connector, a power jack, an ICSP header, and a reset button. It carries everything needed to hold up the microcontroller; simply join it to a data processor with a USB cable or power it with an AC-to-DC adapter or battery to generate gone. The Uno differs from all preceding boards in that it does not use the FTDI USB-to serial driver chip. Instead, it features the Atmega8U2 programmed as a USB-toserial convertor. "Uno" means one in Italian and is named to mark the upcoming release of Arduino 1.0. The Uno and version 1.0 will be the reference versions of Arduino, moving forward. The Uno is the latest in a series of USB Arduino boards, and the reference model for the Arduino platform; for a comparison with previous versions. The Arduino Uno can be powered via the USB connection or with an external power supply. The power source is chosen via the force shift. External (non-USB) power can come either from an AC-to- 
DC adapter (wall-wart) or battery. The adapter can be connected by plugging a $2.1 \mathrm{~mm}$ center-positive plug into the board's power jack. Leads from a battery can be inserted in the Ground and Vin pin headers of the POWER connector.

The board can operate on an external supply of 6 to 20 volts. If supplied with less than $7 \mathrm{~V}$, however, the $5 \mathrm{~V}$ pin may supply less than five volts and the board may be mentally ill. If using more than $12 \mathrm{~V}$, the voltage regulator may overheat and damage the circuit card. The recommended range is 7 to 12 volts.

\section{A. Real Time Clock}

The DS1307 Serial Real-Time Clock is a low-power, full binary-coded decimal (BCD) clock/calendar plus 56 bytes of NV SRAM. Address and data are transferred serially via a 2wire, bi-directional bus. The clock/calendar provides seconds, minutes, hours, day, date, month, and year information. The end of the month date is automatically adjusted for months with fewer than 31 days, including corrections for leap year. The clock operates in either the 24-hour or 12-hour format with AM/PM indicator. The DS1307 has a built-in power sense circuit that detects power failures and automatically switches to the battery supply.

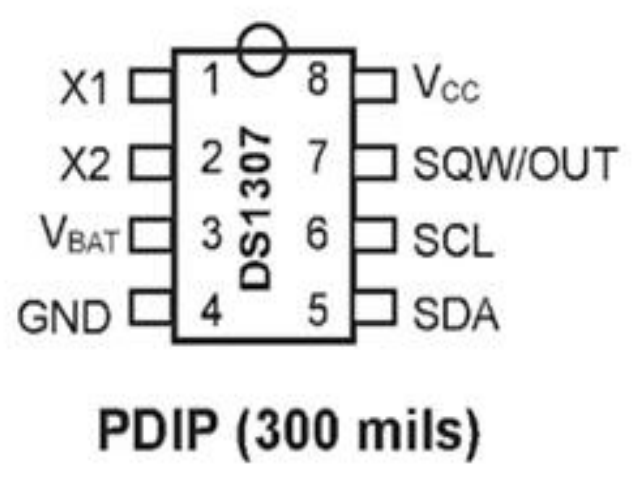

Figure 4: Real Time Clock

\section{B. GPRS}

GSM/GPRS RS232 Modem from built with SIMCOM Make SIM900 Quad-band GSM/GPRS engine, works on frequencies $850 \mathrm{MHz}, 900 \mathrm{MHz}, 1800 \mathrm{MHz}$ and $1900 \mathrm{MHz}$ It is very compact in size and easy to use as plug in GSM Modem. The Modem is designed with RS232 Level converter circuitry, which allows you to directly interface PC Serial port.

The baud rate can be configurable from 9600-115200 through AT command. Initially Modem is in Auto baud mode. This GSM/GPRS RS232 Modem is having internal TCP/IP stack to enable you to connect with internet via GPRS. It is suitable for SMS as well as DATA transfer application in M2M interface. The modem needed only 3 wires ( $\mathrm{Tx}, \mathrm{Rx}$, GND) except Power supply to interface with microcontroller/Host PC. The built in Low Dropout Linear voltage regulator allows you to connect wide. range of un regulated power supply $(4.2 \mathrm{~V}-13 \mathrm{~V})$. Yes, $5 \mathrm{~V}$ is in between!! .Using this modem, you will be able to send \& Read SMS, connect to internet via GPRS through simple AT commands.

\begin{tabular}{lll}
\hline \multicolumn{1}{c}{ Components } & Description \\
\hline 1. Arduino Uno & Atmega328 \\
2. Temperature Sensor & LM 35 \\
3. Moisture Sensor & \\
4. Relays & $5 \mathrm{~V}$ \\
5. GPRS modem & SIM900 \\
6. Transformer & $0-12 \mathrm{~V}$ \\
7. Motor & DC Motor \\
\hline
\end{tabular}

\section{RESULT}

Our workflow of experiments will result in the real time monitoring of the agricultural crops and thus resulting in reducing the unnecessary flow of water to agricultural lands compared to the above methods. In this work real time clock (RTC) which keeps tracking the real time starts and stops the motor at the specified time intervals.

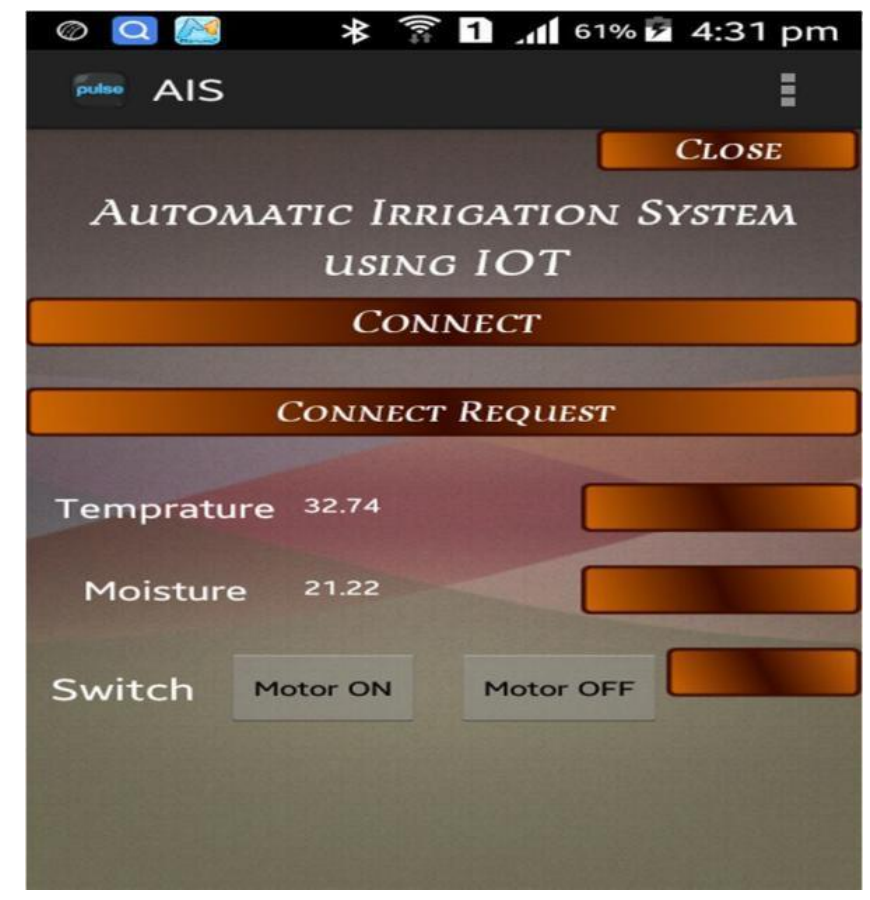

Figure 5: Result

An user friendly android application is created which is capable of running on all the android OS helps the farmer to control the entire unit from anywhere. Comparing to the web pages the android application results in user better friendly interface.

\section{CONCLUSION}

The proposed project helps the farmers in the real time monitoring of crops and also effective usage of water for irrigation by identifying the soil temperature and moisture. This project also helps to water the plants from any remote places. In future we can also implement the mineral deficiency detection by capturing and analyzing the images of crops. 


\section{REFERENCES}

[1] J. Gutiérrez, J.F. Villa-Medina, A. Nieto-Garibay and M.Á. PortaGándara, "Automated irrigation system using a wireless sensor network and GPRS module", IEEE transactions on instrumentation and measurement, Vol. 63, No. 1, Pp. 166-176, 2014.

[2] P. Revathi and C. Rajasekaran, "Energy efficient wireless monitoring system for Agarian areas in Indian agricultural system using GPRS module", In International Conference on Communications and Signal Processing (ICCSP), Pp. 0322-0326, 2015.

[3] S.V. Devika, S. Khamuruddeen, S. Khamurunnisa, J. Thota and K. Shaik, "Arduino Based Automatic Plant Watering System", International Journal of Advanced Research in Computer Science and Software Engineering, Vol. 4, No.10, 2014.

[4] S. Harishankar, R.S. Kumar, K.P. Sudharsan, U. Vignesh and T. Viveknath, "Solar powered smart irrigation system. Advance in Electronic and Electric Engineering", ISSN, Vol. 4, No. 4, Pp. 341-346, 2014

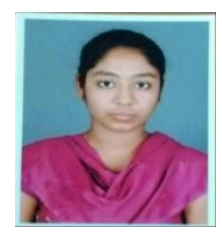

Sharada Kulkarni, (F'21), Studying BE in CSE

SKSVMACET Laxmeshwar-india. (E-mail:

sharadakulkarni69@gmail.com)

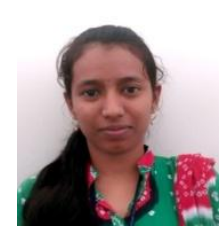

Rekha Mulagund, (F'20), Studying BE in CSE

SKSVMACET, Laxmeshwar-india. (E-mail:

rekhalm123@gmail.com) 